\title{
Risk and mechanism of dexamethasone-induced deterioration of glucose tolerance in non-diabetic first-degree relatives of NIDDM patients
}

\author{
J.E. Henriksen ${ }^{1}$, F. Alford ${ }^{2}$, G. M. Ward ${ }^{2}$, H. Beck-Nielsen ${ }^{1}$ \\ ${ }^{1}$ Diabetes Research Centre, Department of Endocrinology M, Odense University Hospital, Odense, Denmark \\ ${ }^{2}$ Department of Endocrinology and Diabetes, St. Vincent Hospital, Fitzroy, Melbourne, Victoria, Australia
}

Summary We tested the hypothesis that glucose intolerance develops in genetically prone subjects when exogenous insulin resistance is induced by dexamethasone (dex) and investigated whether the steroid-induced glucose intolerance is due to impairment of beta-cell function alone and/or insulin resistance. Oral glucose tolerance (OGTT) and intravenous glucose tolerance tests with minimal model analysis were performed before and following 5 days of dex treatment ( $4 \mathrm{mg} /$ day) in 20 relatives of non-insulin-dependent diabetic (NIDDM) patients and in 20 matched control subjects (age: 29.6 \pm 1.7 vs $29.6 \pm 1.6$ years, BMI: $25.1 \pm 1.0$ vs $25.1 \pm 0.9 \mathrm{~kg} / \mathrm{m}^{2}$ ). Before dex, glucose tolerance was similar in both groups (2-h plasma glucose concentration (PG): $5.5 \pm 0.2$ [range: $3.2-7.0$ ] vs $5.5 \pm 0.2[3.7-7.4] \mathrm{mmol} /$ 1). Although insulin sensitivity ( $\mathrm{Si}$ ) was significantly lower in the relatives before dex, insulin sensitivity was reduced to a similar level during dex in both the relatives and control subjects $(0.30 \pm 0.04$ vs $0.34 \pm$ $0.0410^{-4} \mathrm{~min}^{-1}$ per pmol/l, NS). During dex, the variation in the OGTT 2-h PG was greater in the relatives $(8.5 \pm 0.7[3.9-17.0]$ vs $7.5 \pm 0.3[5.7-9.8] \mathrm{mmol} / \mathrm{l}, \mathrm{F}$ test $p<0.05)$ which, by inspection of the data, was caused by seven relatives with a higher PG than the maximal value seen in the control subjects (9.8 mmol/l). These "hyperglycaemic" relatives had diminished first phase insulin secretion $(\varnothing 1)$ both before and during dex compared with the "normal" relatives and the control subjects (pre-dex $\varnothing 1: 12.6 \pm 3.6$ vs $26.4 \pm 4.2$ and $24.6 \pm 3.6(p<0.05)$, post-dex $\emptyset 1$ : $22.2 \pm 6.6$ vs $48.0 \pm 7.2$ and $46.2 \pm 6.6$ respectively $(p<0.05) \mathrm{pmol} \cdot \mathrm{l}^{-1} \cdot \mathrm{min}^{-1}$ per $\left.\mathrm{mg} / \mathrm{dl}\right)$. However, Si was similar in "hyperglycaemic" and "normal" relatives before dex $\left(0.65 \pm 0.10\right.$ vs $0.54 \pm 0.1010^{-4} \cdot \mathrm{min}^{-1}$ per pmol/l) and suppressed similarly during dex $\left(0.30 \pm 0.07\right.$ vs $0.30 \pm 0.0610^{-4} \cdot \mathrm{min}^{-1}$ per $\left.\mathrm{pmol} / \mathrm{l}\right)$. Multiple regression analysis confirmed the unique importance of low pre-dex beta-cell function to subsequent development of high 2-h post-dex OGTT plasma glucose levels $\left(R^{2}=0.56\right)$. In conclusion, exogenous induced insulin resistance by dex will induce impaired or diabetic glucose tolerance in those genetic relatives of NIDDM patients who have impaired beta-cell function (retrospectively) prior to dex exposure. These subjects are therefore unable to enhance their beta-cell response in order to match the dexinduced insulin resistant state. [Diabetologia (1997) 40: 1439-1448]

Keywords Minimal model analysis, insulin secretion, insulin resistance, relatives of NIDDM patients, steroids, glucose intolerance.
Received: 20 January 1997 and in final revised form: 17 July 1997

Corresponding author: Dr. J.E. Henriksen, Odense University Hospital, Department of Endocrinology M, Klövervaenget 6, DK-5000 Odense C, Denmark

Abbreviations: $\mathrm{AIR}_{\text {glucose }}$, Acute insulin response to intravenous glucose; dex, dexamethasone; FFM, fat free mass; FM, fat mass; GTT, glucose tolerance test; IVGTT, intravenous glucose tolerance test; $\mathrm{Kg}$, intravenous glucose tolerance index; NIDDM, non-insulin-dependent diabetes mellitus; OGTT, oral glucose tolerance test; PG, plasma glucose; Sg, glucose effectiveness; $\varnothing 1$, first phase insulin responsiveness; $\varnothing 2$, second phase insulin responsiveness, $\Delta \mathrm{I}_{30}$ : acute 30 -min insulin response to oral glucose; $\mathrm{Si}$, insulin sensitivity. 
Non-insulin-dependent diabetes mellitus (NIDDM) is associated with insulin resistance and impaired insulin secretion $[1,2]$. First-degree relatives of patients with NIDDM have a $40 \%$ increased risk of developing diabetes [3]. Debate still surrounds the aetiology of the glucose intolerance: whether insulin resistance [4-7] or a beta-cell defect [7-10] is primary in the emergence of the disease $[1,2,11,12]$. Recent studies from our laboratory have shown both the presence of insulin resistance in normal glucose tolerant first-degree relatives of NIDDM subjects $[6,7]$ as well as a subtle defect of insulin secretion [7] in such subjects. However, we demonstrated that glucose tolerance was maintained at normal levels in these subjects through a novel compensatory mechanism of enhanced glucose-mediated glucose disposal or glucose effectiveness [7]. In identical twins discordant for NIDDM, we have also shown that the healthy twins were characterised by a decreased insulin secretion [9]. Together these data support the conclusion of Martin and co-workers [5] that those first-degree relatives with the highest insulin sensitivity and/or glucose effectiveness were the least likely to develop diabetes during their 25-year longitudinal follow-up study [5]. However, despite this latter study, the practical problem remains as to how to identify those normal glucose tolerant individuals who will develop glucose intolerance or frank diabetes, either during times of acute stress and/or in the long term.

Glucocorticoids are known to oppose insulin action at the level of the liver by promoting gluconeogenesis [13] and at the periphery, especially in muscle, by inhibiting glucose uptake [14] and reducing glycogen synthesis and glucose storage [15]. In addition the glucocorticoids are believed to attenuate insulin secretion, particularly the extent of the anticipated hyperinsulinaemic response to the insulin resistant state $[16,17]$. Together these mechanisms are postulated to cause the development of glucose intolerance and diabetes observed in patients exposed to glucocorticoid therapy [13]. However, it is not known which mechanism(s) is primarily responsible for the emergence of diabetes and whether there are any clinical and/or biochemical markers present in an individual prior to exposure to the glucocorticoid which would signal their risk of future glucose intolerance.

Normal glucose tolerant first-degree relatives of NIDDM patients are likely to be at risk of developing glucose intolerance and diabetes following exposure to glucocorticoids, which was already suggested in a series of studies with the oral glucose tolerance test (OGTT) in the mid-1950s by Fajans et al. [18] Conn [19] and Rull et al. [20]. We have studied a group of such individuals prior to and following 5 days of treatment with dexamethasone (dex) as compared to a carefully age-, sex- and weight-matched control group of subjects with no family history of diabetes. The frequently sampled intravenous glucose tolerance test with the minimal model approach to analysis of the glucose and insulin profiles $[21,22]$ was employed in order to simultaneously measure the interplay between insulin secretion, insulin sensitivity and the mass action effect of glucose per se (glucose effectiveness) on glucose tolerance.

Our aim was twofold: first, to determine whether the effect of dex on glucose tolerance differs between relatives of NIDDM patients and subjects with no family history of diabetes; and second, to delineate which clinical and/or biochemical feature(s) present in subjects prior to dex treatment would allow the prediction of post-dex glucose intolerance and/or diabetes.

\section{Subjects and methods}

Subjects. First-degree relatives (children) of NIDDM patients were traced through patients with verified NIDDM from the Department of Endocrinology, Odense University Hospital. Twenty subjects with at least two first-degree relatives with NIDDM or one first degree relative and at least one seconddegree relative with NIDDM were included in the study. All of the relatives had normal oral glucose tolerance and had not been prescribed any medication known to influence glucose homeostasis prior to the treatment with dex. The relatives were matched according to age, sex, and BMI to a group of normoglycaemic control subjects without any family history of NIDDM and their clinical characteristics are given in Table 1. Pre-dex data (see below) for the same study population have previously been published [7].

Protocol. The subjects were studied on two occasions not more than 3 weeks apart. First, subjects were examined without medication (pre-dex) and second, subjects were examined during treatment with dex (post-dex). On both occasions an oral glucose tolerance test (OGTT) and an intravenous glucose tolerance test (IVGTT) were performed in the fasting state. For the post-dex studies, $2 \mathrm{mg}$ of dex was given twice daily for 5 days. On days 4 and 5 , dex $(2 \mathrm{mg})$ was given at 07.00 hours and the OGTT or IVGTT performed at 09.00 hours. In order to standardise the physical activity level between studies, the subjects were admitted to the hospital in the evening on day 4 and served a light meal at 20.00 hours (the same procedure was used the day before the IVGTT for the pre-dex study), and dex was given at 23.00 hours.

The OGTT was performed by ingestion of $75 \mathrm{~g}$ glucose in a liquid solution. Blood samples were obtained in the fasting state (three samples) and for a total of $3 \mathrm{~h}$ following the glucose load (15 samples). For the IVGTT a $25 \%$ solution of glucose was given i. v. over $60 \mathrm{~s} \mathrm{(300} \mathrm{mg/body} \mathrm{weight,} \mathrm{maximally}$ $25 \mathrm{~g}$ ) and multiple blood samples obtained in the fasting state (4 samples) and for a total of $3 \mathrm{~h}$ following the i.v. glucose load (26 samples) [7]. Blood samples were analysed for plasma glucose and insulin concentrations, but for plasma C-peptide concentrations in the fasting samples only.

Total fat mass (FM) and fat free mass (FFM) were estimated by the bioimpedance method [23] and the latter calculated as the difference between body weight and FM. Body mass index (BMI) (body weight $(\mathrm{kg}) /$ height $^{2}(\mathrm{~m})$ ) was also calculated. Waist circumference was measured at the level of the umbilicus and the hip circumference at the level of the greater trochanter. The protocol was approved by the local ethics 
Table 1. Physical characteristics of the study subjects before and during dex treatment

\begin{tabular}{|c|c|c|c|c|}
\hline & \multicolumn{2}{|l|}{ Relatives } & \multicolumn{2}{|c|}{ Control subjects } \\
\hline & Pre & Post & Pre & Post \\
\hline$n$ of subjects (female, male) & $20(8 / 12)$ & & $20(8 / 12)$ & \\
\hline Waist-hip ratio (\%) & $0.88 \pm 0.02$ & & $0.89 \pm 0.02$ & \\
\hline $\mathrm{HbA}_{1 \mathrm{c}}(\%)$ & $6.17 \pm 0.13$ & & $6.12 \pm 0.08$ & \\
\hline $\operatorname{BMI}\left(\mathrm{kg} / \mathrm{m}^{2}\right)$ & $25.1 \pm 1.0$ & $25.1 \pm 1.1$ & $25.1 \pm 0.9$ & $25.0 \pm 0.9$ \\
\hline Weight $(\mathrm{kg})$ & $76.6 \pm 3.3$ & $76.7 \pm 3.6$ & $78.8 \pm 4.0$ & $78.7 \pm 4.1$ \\
\hline Fat mass/Fat free mass ratio $(\%)$ & $37 \pm 4$ & $39 \pm 4$ & $36 \pm 4$ & $38 \pm 4$ \\
\hline Triglyceride $(\mathrm{mmol} / \mathrm{l})$ & $1.11 \pm 0.13$ & $1.06 \pm 0.09$ & $0.96 \pm 0.07$ & $1.09 \pm 0.07$ \\
\hline Cholesterol (mmol/l) & $5.05 \pm 0.25$ & $5.16 \pm 0.29$ & $4.57 \pm 0.19$ & $4.63 \pm 0.17$ \\
\hline HDL cholesterol (mmol/l) & $1.31 \pm 0.07$ & $1.50 \pm 0.08^{\mathrm{a}}$ & $1.26 \pm 0.06$ & $1.37 \pm 0.08^{\mathrm{a}}$ \\
\hline LDL cholesterol (mmol/1) & $3.25 \pm 0.26$ & $3.17 \pm 0.30$ & $2.90 \pm 0.20$ & $2.77 \pm 0.17$ \\
\hline Fasting glucose $(\mathrm{mmol} / \mathrm{l})$ & $5.41 \pm 0.08$ & $5.70 \pm 0.12^{b}$ & $5.16 \pm 0.08^{c}$ & $5.38 \pm 0.06^{\mathrm{a}, \mathrm{c}}$ \\
\hline
\end{tabular}

Values are mean \pm SEM. Normal range of $\mathrm{HbA}_{1 \mathrm{c}} 5.4-7.4 \%$.

${ }^{\mathrm{a}} p<0.05 ;{ }^{\mathrm{b}} p<0.005$ vs pre-dex value; ${ }^{\mathrm{c}} p<0.05$ control subjects vs relatives

committee and informed written consent was obtained from all participants before testing.

Assays. Plasma glucose concentration was measured at the bedside by the glucose oxidase method with a Glucose Analyzer (Beckman Instruments, Inc., Fullerton, Calif., USA). Blood samples for plasma insulin were immediately centrifuged at $4^{\circ} \mathrm{C}$ at the time of study and stored at $-20^{\circ} \mathrm{C}$ until analysis and concentrations measured by a double antibody radioimmunoassay in duplicate (Kabi Pharmacia Diagnostics AB, Uppsala, Sweden). Within-assay coefficient of variation was $5.6 \%$; inter-assay variation was $6.2 \%$; and cross-reactivity with proinsulin was $40 \%$. Plasma C-peptide was measured by a two-site, time-resolved immunofluorometric assay (DELFIA, Wallac Oy, Turku, Finland) [24]. Triglyceride was measured by an enzymatic colorimetric method as was cholesterol (Wako Chemicals GmbH, Neuss, Germany). $\mathrm{HbA}_{1 \mathrm{c}}$ was estimated by HPLC (normal range 5.4 to $7.4 \%$ ).

Calculations. For the measurements of insulin and glucose sensitivities and insulin secretion, the analysis of the IVGTT data was based on Bergman's minimal model of glucose disappearance [21] and insulin kinetics [22]. Glucose and insulin profiles were analysed as formerly described using the program, Simulation Analysis and Modelling (SAAM) together with the conversational part of the program (CONSAM) [25, 26]. This approach allows for the simultaneous measurements of the model parameters ( $\mathrm{Si}$, insulin sensitivity; $\mathrm{Sg}$, glucose effectiveness or sensitivity; $\varnothing 1$ and $\varnothing 2$, insulin secretory parameters) without the use of intravenous tolbutamide [25]. Although first $(\varnothing 1)$ and second phase insulin profiles $(\varnothing 2)$ were quantified by the modelling procedure [22], the acute insulin response to intravenous glucose $\left(\mathrm{AIR}_{\text {glucose }}\right)$ was also calculated as the mean of the incremental plasma insulin concentration above basal from 0-10 min following the iv glucose bolus [27]. In addition, the acute 30-min insulin response to the OGTT was calculated as the incremental change in the OGTT plasma insulin concentrations from 0' to 30' $\left(\Delta \mathrm{I}_{30}\right)$. The rate of intravenous glucose disappearance $(\mathrm{Kg})$, a measure of overall glucose tolerance, was determined as the least-square slope of the ln of the glucose concentration between 12 and 30 minutes after the glucose bolus. In order to decrease the ratio of unknown variables in the minimal model equations to the number of observations (plasma glucose and insulin concentrations) the pre- and post-dex IVGTTs were modelled simultaneously as previously described $[25,28]$. In brief we analysed the glucose and insulin profiles from the paired studies, fitting both models simultaneously to the glucose and insulin data. This approach optimizes the analysis so as to determine those parameter values common to both sets of data and those that are unique to the experimental perturbation, and thus reduce the errors of the estimated parameters $[25,28]$. The rationale for this method of analysis is based on the minimal changes postulate of Boston and Weber [29] as originally advanced by Berman [30].

Statistical analysis. The results are presented as mean \pm SEM. Differences between the groups were compared by MannWhitney rank-sum test. Paired comparisons were performed using the Wilcoxon matched-pairs signed-ranks test. None of these analyses by non-parametric methods were altered if the data were subjected to logarithmic transformation to normalise the data and paired or unpaired $t$-test employed (data not shown). Correlation analyses were performed using Spearman rank sum correlation analysis. $p$-values of 0.05 or less were considered significant.

\section{Results}

Pre-dex anthropometric measurements including waist-hip ratio (WHR), basal lipid status and fasting insulin values were similar in both groups apart from fasting glucose and fasting C-peptide which were significantly higher in the relative group (Table 1) as previously reported [7]. After exposure to dex the only variables to change were significant rises in fasting plasma glucose and HDL cholesterol $(p<0.05)$, and insulin and C-peptide levels $(p<0.005)$ for both the relative and control groups (Table 1).

Plasma glucose and insulin concentrations obtained during the OGTT before and during dex treatment are shown in Figure 1. No differences in the predex OGTT plasma glucose concentrations existed 

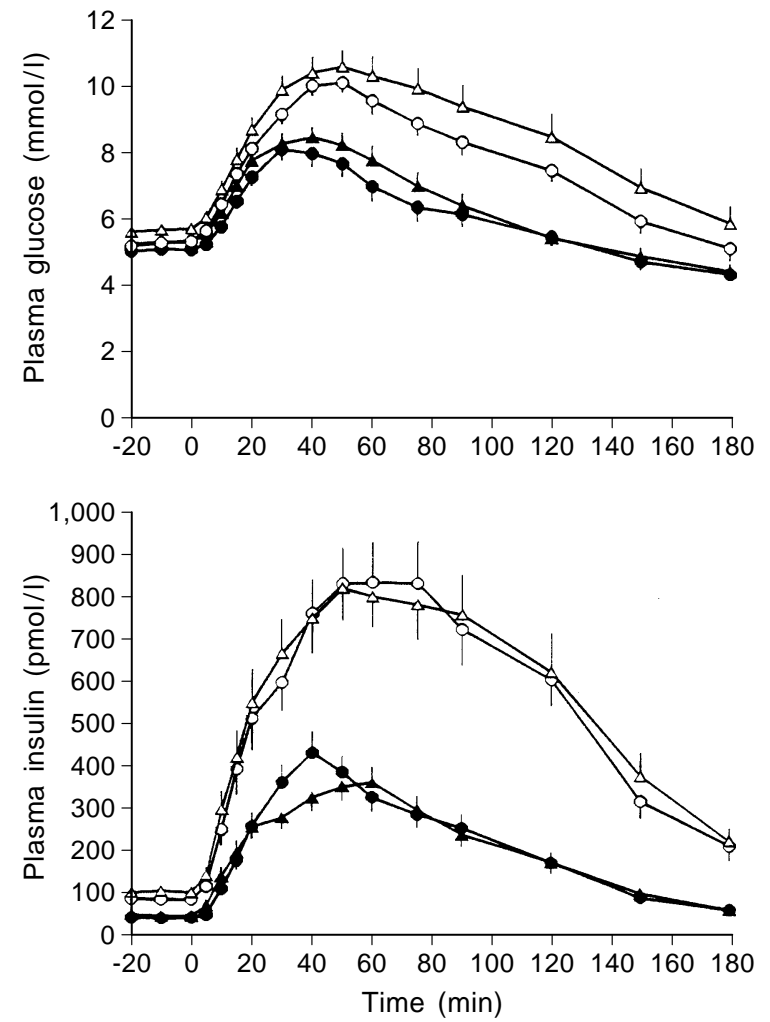

Fig.1. Plasma glucose and insulin concentrations in relatives of NIDDM patients (triangles) and in control subjects (circles) during the OGTT before (closed symbols) and during (open labels) dex treatment. Values are mean \pm SEM

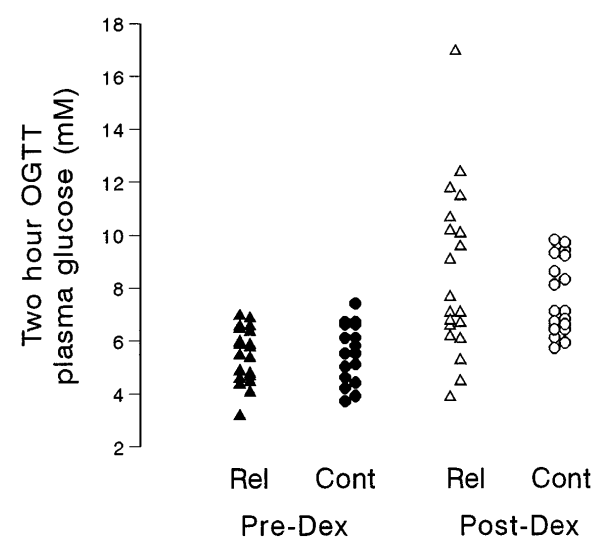

Fig. 2. Two-hour plasma glucose concentration during the OGTT before and during dex treatment

between relatives and control subjects (Fig.1). During treatment with dex glucose tolerance deteriorated in both groups, but post-dex a separation of the control subjects from the relatives occurred (Fig.1). When the individual 2-h plasma glucose concentrations before and during dex treatment were plotted, a clear difference between control subjects and relatives is evident (Fig. 2). First, the distributions of the 2-h plasma glucose concentrations during dex are significantly different in the two groups, with a number of relatives having higher glucose levels and three subjects lower levels (Fig. 2$)$ ( $F$-test, $p<0.05)$, although no difference existed between the groups with respect to the mean 2-h plasma glucose concentration during dex treatment. Second, post-dex, seven relatives had plasma glucose concentrations greater than the highest concentration observed for the control subjects (Fig. 2), with four of these relatives having glucose levels in the World Health Organization (WHO) diagnostic range for diabetes. However, despite these differences in the post-dex plasma glucose OGTT profiles, post-dex mean plasma insulin concentrations in control and relative subjects were similar in both groups (Fig. 1).

Similar to the post-dex OGTT glucose and insulin profiles, post-dex a small increase was observed in the IVGTT plasma glucose concentrations but a large increase occurred in the plasma insulin concentrations compared to the pre-dex values for both relative and control groups. No differences were evident in insulin profiles between relatives and control subjects post-dex, and the intravenous glucose tolerance index $\mathrm{Kg}$ was similar in relative and control groups both pre- and post-dex (Table 2). Nevertheless from the minimal model analysis of the FSIGT glucose effectiveness $(\mathrm{Sg})$ was significantly increased in the relatives compared to the control subjects before treatment with dex [7], and post-dex Sg remained significantly raised in the relative group (Table 2), with no change in $\mathrm{Sg}$ in either group after exposure to dex (Table 2). In contrast, despite the higher Si in the control group pre-dex compared to the relative group $\left(0.80 \pm 0.10\right.$ vs $0.58 \pm 0.0710^{-4} \mathrm{~min}^{-1}$ per $\mathrm{pmol} / 1$, $p=0.05)$ Si fell significantly in both groups post-dex and were in absolute terms similar to each other post-dex (Table 2). It was noted that subjects with the highest pre-dex $\mathrm{Si}$ seemed to have the most marked relative reduction in Si during dex, which was confirmed by a significant correlation between the pre-dex $\mathrm{Si}$ and the fall in $\mathrm{Si}$ (pre-dex $\mathrm{Si}$ minus post-dex $\mathrm{Si})(R=0.86, \quad p<0.00001, n=40)$. First phase insulin release, whether expressed as acute insulin response to glucose $\left(\mathrm{AIR}_{\text {glucose }}\right)$, the model parameter $\varnothing 1$, or the acute insulin response to the $\operatorname{OGTT}\left(\Delta \mathrm{I}_{30}\right)$, and the model derived second phase insulin responsiveness (Ø2), were markedly increased in both groups post-dex (Table 2). However, the glucose assimilation index $(\mathrm{Si} \times \emptyset 1)$, which is a measure of total insulin mediated glucose disposal $[7,31]$, was significantly lower in the relatives postdex, but the decrement in response to dex was similar for both groups (Table 2).

As noted above, the heterogeneity of responses to dex for glucose tolerance in the relative group revealed an apparent subgroup of seven relatives, who had 2-h OGTT plasma glucose concentrations above those found in the control group (Fig.2). This subgroup (hyper-rel) was therefore further examined 
Table 2. Glucose and insulin kinetic parameters derived from the frequently sampled intravenous glucose tolerance test and OGTT obtained during dex treatment and changes from baseline in relatives of NIDDM subjects and in control subjects

\begin{tabular}{|c|c|c|c|c|}
\hline & \multicolumn{2}{|l|}{ Relatives } & \multicolumn{2}{|c|}{ Control subjects } \\
\hline & Dex & Change & Dex & Change \\
\hline $\operatorname{Kg}\left(10^{-2} \min ^{-1}\right)$ & $1.39 \pm 0.10$ & $-0.21 \pm 0.14$ & $1.42 \pm 0.11$ & $-0.17 \pm 0.12$ \\
\hline $\mathrm{Si}\left(10^{-4} \mathrm{~min}^{-1}\right.$ per $\left.\mathrm{pmol} / \mathrm{l}\right)$ & $0.30 \pm 0.04$ & $-0.28 \pm 0.08^{\mathrm{b}}$ & $0.34 \pm 0.04$ & $-0.46 \pm 0.09^{\mathrm{d}}$ \\
\hline $\mathrm{AIR}_{\text {glucose }}(\mathrm{pmol} / \mathrm{l})$ & $283 \pm 40$ & $197 \pm 35^{\mathrm{d}}$ & $307 \pm 48$ & $253 \pm 50^{\mathrm{d}}$ \\
\hline$\Delta \mathrm{I}_{30}(\mathrm{pmol} / \mathrm{l})$ & $301 \pm 49$ & $165 \pm 37^{c}$ & $278 \pm 41$ & $134 \pm 33^{c}$ \\
\hline$\varnothing 1\left(\mathrm{pmol} \cdot \mathrm{l}^{-1} \cdot \mathrm{min}^{-1}\right.$ per $\left.\mathrm{mg} / \mathrm{dl}\right)$ & $39.1 \pm 6.0$ & $17.8 \pm 3.6^{\mathrm{c}}$ & $45.9 \pm 6.7$ & $21.1 \pm 4.0^{\mathrm{d}}$ \\
\hline
\end{tabular}

Values are mean \pm SEM. Kg, Intravenous glucose tolerance index; $\mathrm{Sg}$, glucose effectiveness; $\mathrm{Si}$, insulin sensitivity index; $\mathrm{AIR}_{\text {glucose }}$, acute insulin response to glucose; $\varnothing 1$, first phase insulin responsiveness; $\varnothing 2$, second phase insulin responsiveness; $\mathrm{Si} \times \varnothing 1$, glucose assimilation index.
${ }^{\mathrm{a}} p<0.01 ;{ }^{\mathrm{b}} p<0.005 ;{ }^{\mathrm{c}} p<0.0005 ;{ }^{\mathrm{d}} p<0.0001$ different from zero; ${ }^{\mathrm{e}} p<0.05$ control subjects vs relatives

Table 3. Glucose and insulin kinetic parameters derived from the frequently sampled intravenous glucose tolerance test obtained before and during dex treatment in hyperglycaemic and normoglycaemic relatives and in control subjects

\begin{tabular}{|c|c|c|c|}
\hline & \multicolumn{2}{|l|}{ Relatives } & \multirow[t]{2}{*}{ Control subjects } \\
\hline & Hyperglycaemic & Normoglycaemic & \\
\hline $\begin{array}{l}\text { Pre-dex values } \\
\mathrm{Kg}\left(10^{-2} \mathrm{~min}^{-1}\right) \\
\mathrm{Sg}\left(10^{-2} \mathrm{~min}^{-1}\right) \\
\mathrm{Si}\left(10^{-4} \mathrm{~min}^{-1} \text { per } \mathrm{pmol} / \mathrm{l}\right) \\
\Delta \mathrm{I}_{30}(\mathrm{pmol} / \mathrm{l}) \\
\mathrm{AIR}_{\text {glucose }}(\mathrm{pmol} / \mathrm{l}) \\
\varnothing 1\left(\mathrm{pmol} \cdot \mathrm{l}^{-1} \cdot \mathrm{min}^{-1} \text { per } \mathrm{mg} / \mathrm{dl}\right) \\
\varnothing 2\left(\mathrm{pmol} \cdot \mathrm{l}^{-1} \cdot \mathrm{min}^{-2} \text { per } \mathrm{mg} / \mathrm{dl}\right) \\
\mathrm{Si} \times \varnothing 1\left(10^{-4} \mathrm{~min}^{-2} \text { per } \mathrm{mg} / \mathrm{dl}\right)\end{array}$ & $\begin{array}{l}1.33 \pm 0.16 \\
1.83 \pm 0.31 \\
0.65 \pm 0.10 \\
78 \pm 18 \\
177 \pm 47 \\
12.5 \pm 3.5 \\
57.5 \pm 7.3 \\
7.52 \pm 2.47\end{array}$ & $\begin{array}{c}1.74 \pm 0.19 \\
1.98 \pm 0.54 \\
0.54 \pm 0.10 \\
167 \pm 25^{\mathrm{c}} \\
340 \pm 50^{\mathrm{c}} \\
26.2 \pm 4.0^{\mathrm{c}} \\
63.8 \pm 8.9 \\
13.58 \pm 2.99\end{array}$ & $\begin{array}{c}1.59 \pm 0.17 \\
1.52 \pm 0.16 \\
0.80 \pm 0.10 \\
114 \pm 16^{\mathrm{a}} \\
307 \pm 48 \\
24.8 \pm 3.7^{\mathrm{a}} \\
54.7 \pm 10.3 \\
16.72 \pm 1.97^{\mathrm{a}}\end{array}$ \\
\hline $\begin{array}{l}\text { Post-dex values } \\
\mathrm{Kg}\left(10^{-2} \mathrm{~min}^{-1}\right) \\
\mathrm{Sg}\left(10^{-2} \mathrm{~min}^{-1}\right) \\
\mathrm{Si}\left(10^{-4} \mathrm{~min}^{-1} \text { per } \mathrm{pmol} / \mathrm{l}\right) \\
\Delta \mathrm{I}_{30}(\mathrm{pmol} / \mathrm{l}) \\
\mathrm{AIR} \text { glucose }(\mathrm{pmol} / \mathrm{l}) \\
\emptyset 1\left(\mathrm{pmol} \cdot \mathrm{l}^{-1} \cdot \mathrm{min}^{-1} \text { per } \mathrm{mg} / \mathrm{dl}\right) \\
\varnothing 2\left(\mathrm{pmol} \cdot \mathrm{l}^{-1} \cdot \mathrm{min}^{-2} \text { per } \mathrm{mg} / \mathrm{dl}\right) \\
\mathrm{Si} \times \varnothing 1\left(10^{-4} \mathrm{~min}^{-2} \text { per } \mathrm{mg} / \mathrm{dl}\right)\end{array}$ & $\begin{array}{c}1.23 \pm 0.18 \\
1.90 \pm 0.29 \\
0.30 \pm 0.07 \\
182 \pm 57 \\
322 \pm 82 \\
22.2 \pm 17.9 \\
82.7 \pm 46.0 \\
5.50 \pm 1.15\end{array}$ & $\begin{array}{c}1.48 \pm 0.11 \\
1.98 \pm 0.23 \\
0.30 \pm 0.06 \\
366 \pm 64^{\mathrm{c}} \\
565 \pm 60 \\
48.2 \pm 26.8^{\mathrm{c}} \\
96.8 \pm 13.9 \\
12.52 \pm 2.47^{\mathrm{c}}\end{array}$ & $\begin{array}{c}1.42 \pm 0.49 \\
1.44 \pm 0.13 \\
0.34 \pm 0.04 \\
278 \pm 41 \\
560 \pm 90^{\mathrm{a}} \\
45.9 \pm 6.7^{\mathrm{a}} \\
103.5 \pm 21.7 \\
14.38 \pm 1.70^{\mathrm{b}}\end{array}$ \\
\hline
\end{tabular}

Values are mean \pm SEM. $\mathrm{Kg}$, Intravenous glucose tolerance index; $\mathrm{Sg}$, glucose effectiveness; $\mathrm{Si}$, insulin sensitivity index; $\Delta \mathrm{I}_{30}$, acute insulin response to oral glucose; $\mathrm{AIR}_{\text {glucose }}$, acute insulin response to IV glucose; $\varnothing 1$, first phase insulin responsiveness; $\varnothing 2$, second phase insulin responsiveness; Si $\times \varnothing 1$, glucose assimilation index.

with respect to the interplay between glucose effectiveness, $\mathrm{Si}$ and insulin secretion and was compared to the normoglycaemic relatives (norm-rel, $n=13$ ) and control group (Con, $n=20$ ) (Table 3 ). No statistical differences in $\mathrm{Kg}$ and $\mathrm{Sg}$ between any of the subgroups were noted pre- and post-dex although Sg remained $20 \%$ higher in both relative subgroups compared to the control group (Table 3). However, first phase insulin release, expressed as either $\mathrm{AIR}_{\text {glucose }}$ or the minimal model derived $\varnothing 1$, or the OGTT $\Delta \mathrm{I}_{30}$, was significantly reduced by about $50 \%$ in the hyper-rel subgroup compared to the norm-rel
${ }^{\mathrm{a}} p<0.05,{ }^{\mathrm{b}} p<0.005$, control subjects vs hyperglycaemic relatives, ${ }^{\mathrm{c}} p<0.05$, normoglycaemic relatives vs hyperglycaemic relatives

subgroup of the relatives and the control group, both pre- and post-dex (Fig. 3 and Table 3). A similar $50 \%$ reduction was also noted for the glucose assimilation index $(\mathrm{Si} \times \varnothing 1)$ for the hyper-rel subgroup preand post-dex (Table 3 ). Furthermore, a dex-induced approximate twofold incremental rise in first phase insulin release $\left(\mathrm{AIR}_{\text {glucose }}, \varnothing 1\right.$ or $\left.\Delta \mathrm{I}_{30}\right)$ was clearly evident in the norm-rel and control groups $(p<0.001)$ but no significant increase was observed in the hyper-rel group (Table 3). Finally, as mentioned above, three relatives of the norm-rel subgroup had a lower 2-h post-dex plasma glucose concentration than the 


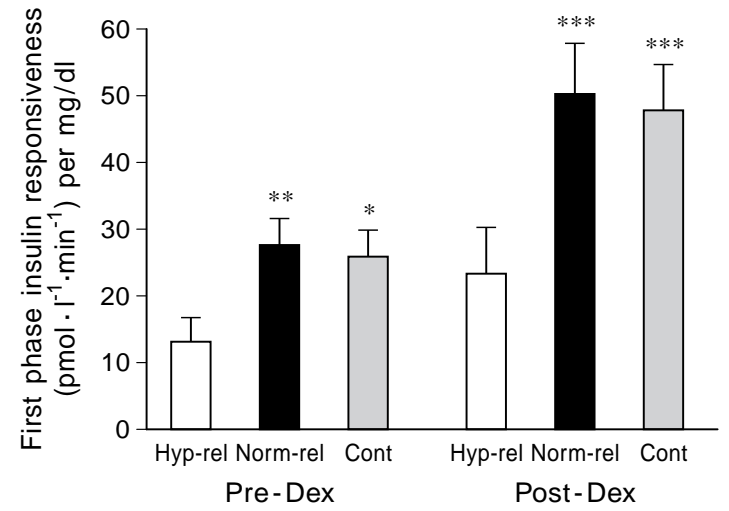

Fig.3. First phase insulin responsiveness $(\varnothing 1)$ pre- and postdexamethasone in hyperglycaemic $(\square)$ and normoglycaemic relatives $(\square)$ and in control subjects (潾). Values are mean \pm SEM. $* p<0.05, * * p<0.03$, *** $p<0.02$ vs hyperglycaemic relatives

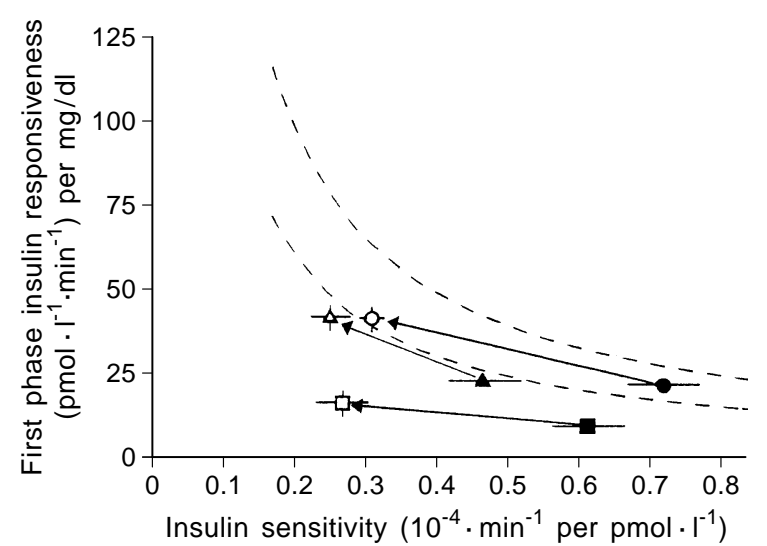

Fig.4. Relationship between insulin sensitivity and insulin secretion in hyperglycaemic $(\square, \boldsymbol{\square})$ and normoglycaemic $(\triangle, \boldsymbol{\Delta})$ relatives of NIDDM patients and in control subjects $(\mathbf{O}, \bigcirc)$, before (closed symbols) and during (open symbols) dex treatment. Arrows indicate direction of movement of respective groups following dex treatment. Dotted lines represent the $95 \%$ confidence limits obtained from the antilog of the $95 \%$ confidence limits for the log transformed data for the control group pre-dex. Values are mean \pm SEM

lowest concentration observed in the control group. These relatives with respect to pre- and post-dex insulin secretion were characterised by very high first phase insulin secretion both pre- and post-dex (predex AIR glucose $_{\text {e }} 439 \pm 59 \mathrm{pmol} / \mathrm{l}$, post-dex AIR $_{\text {glucose }}$ : $743 \pm 152 \mathrm{pmol} / \mathrm{l}$, pre-dex OGTT $\Delta \mathrm{I}_{30}: 315 \pm 3 \mathrm{pmol} / 1$ and post-dex OGTT $\left.\Delta \mathrm{I}_{30}: 554 \pm 103 \mathrm{pmol} / \mathrm{l}\right)$ as compared to the control group (Table 3 ), whereas $\mathrm{Si}$ in the three relatives was reduced $\left(0.33 \pm 0.07 \cdot 10^{-4}\right.$ $\mathrm{min}^{-1}$ per $\mathrm{pmol} / \mathrm{l}$ ) prior to treatment with dexamethasone, indicating an effective preservation of a normal acute phase insulin release compared to Si relationship in these three relatives [32]. To gain further insight into the interrelationship between $\mathrm{Si}$ and $\varnothing 1$, we plotted the mean Si index against the mean values of $\varnothing 1$ in the hyper-rel and norm-rel subgroups of the relatives and the control group (Fig. 4). The dotted lines in Figure 4 indicate the upper and lower range of the $95 \%$ confidence limit for the pre-dex control group which represent the limits of the appropriateness of the insulin response to the prevailing $\mathrm{Si}$ of the control subjects; as explained below, it does not indicate normality of glucose tolerance. Following exposure to dex $\mathrm{Si}$ was significantly decreased in the control subjects and this was almost completely compensated for by the increase in the first phase insulin responsiveness i.e. remained in the normal range (open circle, Fig. 4). As reported previously [7] relatives before treatment with dex are characterised by a reduced Si and inappropriate $\varnothing 1$ for their prevailing $\mathrm{Si}$ and lie just below the normal range (represented here by solid triangle (norm-rel) and solid square (hyper-rel) in Fig.4). Following dex exposure an important difference emerged in these two subgroups of relatives despite a similar degree of dex-induced insulin insensitivity (Fig. 4, open square and open triangle, respectively). In the hyper-rel subgroup of the relatives a failure of the $\varnothing 1$ to respond to dex (open square, Fig.4). In contrast the norm-rel subgroup had an appropriate $\varnothing 1$ response comparable to control subjects, and $\varnothing 1$ remained very close to the normal range (open triangle, Fig. 4). Thus, first phase insulin release $\varnothing 1$ and the glucose assimilation index $(\mathrm{Si} \times \varnothing 1)$ are central factors in the development of the raised 2-h OGTT glucose levels noted in the hyper-rel subgroup of the relatives post-dex. Interestingly, the key clinical characteristics present in the hyper-rel subgroup before exposure to dex were a higher fasting serum triglyceride concentration $(1.53 \pm 0.28$ vs $0.88 \mathrm{mmol} / \mathrm{l}, p<0.01)$ and a higher LDL/HDL cholesterol ratio (3.21 \pm 0.42 vs $2.51 \pm 0.55, p<0.05)$ as compared to the norm-rel subgroup.

Finally, because of the arbitrary nature of the definition of the relative subgroups, we examined as a continuum the relationships between the post-dex 2$\mathrm{h}$ OGTT plasma glucose level and the pre-dex fasting triglyceride $(r=0.50, p<0.03)$, the pre-dex $\mathrm{AIR}_{\text {glucose }}$ $(r=-0.45, p<0.05)$ and the pre-dex OGTT $\Delta \mathrm{I}_{30}$ $(r=-0.68, p<0.001)$ in the relative group as a whole and these were all significant. This was not so for the control group. When these data were subjected to multiple regression analysis with the dependent variable being the post-dex 2-h OGTT plasma glucose concentration, and the independent variables being the pre-dex clinical characteristics of the subjects and the parameters from the IVGTT, the pre-dex fasting triglyceride concentration and $\mathrm{AIR}_{\text {glucose }}$ were significant determinators of the post-dex 2-h OGTT plasma glucose concentration in the relative group $(2-\mathrm{h}$ glucose $=5.7+4.27 \times$ triglyceride $0.0062 \times \mathrm{AIR}_{\text {glucose }}, R^{2}=0.56$ ). Moreover, on repeating the regression analysis with the pre-dex $\Delta \mathrm{I}_{30}$ from the OGTT rather than the $\mathrm{AIR}_{\text {glucose, }}$ the predex 
fasting triglyceride concentration and the $\Delta \mathrm{I}_{30}$ remained significant determinators of the 2 -h post-dex plasma glucose concentration $(2-\mathrm{h}$ glucose $=7.29+$ $3.52 \times$ triglyceride $\left.-0.019 \times \Delta \mathrm{I}_{30}, R^{2}=0.69\right)$ in the relatives.

\section{Discussion}

More than 40 years ago Fajans et al. [18] suggested that a single-dose cortisone-modified oral glucose tolerance test (cortisone-GTT) could be a tool by which relatives of NIDDM patients could be separated into relatives prone to develop diabetes and those who are not. Later they reported that prospectively (7year follow-up) $35 \%$ of their relatives initially investigated with cortisone induced glucose intolerance had developed diabetes whereas only $2 \%$ of the relatives with an initially negative response to the cortisone-GTT did so [19]. Moreover, they showed that relatives with a positive cortisone-GTT had reduced and delayed insulin response during the cortisoneGTT compared to the relatives with a negative response [20].

We have previously reported that non-diabetic relatives of NIDDM patients have reduced Si compared to control subjects, and that first phase insulin responsiveness is reduced relative to their Si despite normal oral and intravenous glucose tolerance [7]. We postulated that these insulin-resistant relatives of NIDDM patients maintain "normal" glucose tolerance because of their significantly increased glucose effectiveness (glucose mediated glucose disposal) compared to the control subjects. Thus, given the previous suggestion of Fajans et al. [18] that a short period of exposure to glucocorticoids could be helpful in discriminating between relatives prone to develop diabetes and those who are not, it was important to determine the mechanism(s) - altered insulin secretion, $\mathrm{Si}$ or glucose effectiveness or a combination of these parameters - responsible for deterioration in glucose tolerance following exposure to dex. Dex was chosen because it is known to induce insulin resistance via an inhibition of glucose uptake [13] and reduction in the glucose storage pathway [14] and to attenuate the expected beta-cell response to insulin resistance $[16,17]$. Our hypothesis was that dex treatment could unmask relatives who had the genetic susceptibility either to worsen their insulin resistance and/or to decompensate Si leading to the development of glucose intolerance. Thus, we wished to mimic the stress of "time" on the biological system in these subjects. That is, the reduced Si induced by the dex treatment and its potential to limit the beta-cell response to this stress [17] could parallel the changes observed over time with increasing age, obesity and sedentary lifestyle, including the phenomena of "fatigue" of the beta cell.
In the present study we demonstrated that exposure to dex for 5 days could separate a subgroup of relatives of NIDDM patients from subjects with no family history of diabetes. Of the 20 relatives studied, 7 had a higher 2-h post-dex OGTT plasma glucose concentration than the highest noted for the control group. Four of these subjects developed transient diabetes according to the WHO criteria (all subjects returned to normal glucose tolerance when re-examined 1 week after the discontinuation of dexamethasone). These seven relatives with severe glucose intolerance during dex treatment had a lower insulin secretory capacity and glucose assimilation index $(\mathrm{Si} \times \varnothing 1)$ than the control subjects and the "normoglycaemic" relatives both before and during dex treatment. Importantly the deterioration of their glucose tolerance with dex treatment occurred despite the persistent raised glucose effectiveness $(\mathrm{Sg})$ both pre- and post-dex.

In the pre-dex situation, oral and intravenous glucose tolerance are comparable in the relatives and control subjects, but the mechanism underpinning the normal glucose tolerance differs between relatives and control subjects. For the former group, glucose mediated glucose disposal is more pronounced, representing about $64 \%$ of overall glucose disposal, whereas insulin mediated glucose disposal is more important in the control subjects representing $58 \%$ of glucose disposal [7]. In response to dexamethasone, glucose effectiveness (glucose mediated glucose disposal) did not change in either of the relative groups, and their raised "protective" glucose effectiveness remained during dex treatment despite the development of glucose intolerance. It therefore could be speculated that either the increased pre-dex glucose mediated glucose disposal in the relatives is maximally compensating before treatment with dex or that the physiologic mechanism behind the increased glucose mediated glucose disposal cannot adapt during a short period of dex exposure and worsening insulin resistance. Other studies have previously shown in normal healthy subjects that glucose mediated glucose disposal is not influenced by short term glucocorticoids, either when measured by the hyperglycaemic clamp at "zero" insulin [33] or more recently when measured by the minimal model analysis of the IVGTT [17, 34]. Following dexamethasone treatment fasting plasma glucose concentration increase a similarly in both groups, which would be consistent with an increased hepatic glucose production during dexamethasone treatment in both groups [11, 35]. With the minimal model frequently sampled intravenous glucose tolerance analysis it is, however, impossible to ascertain whether there was any difference in hepatic glucose production between relatives and control subjects, as the technique does not separate glucose mediated glucose disposal into its two major components $[7,28]$; i.e. the effect of 
hyperglycaemia itself to enhance peripheral glucose uptake and suppress hepatic glucose production [31, 36]. Nevertheless, regardless of whether dexamethasone induced either hepatic insulin or hepatic glucose resistance, whole body $\mathrm{Sg}$ was unchanged in both the relatives and control subjects.

The mechanism of glucocorticoid-induced insulin resistance has been studied extensively [13]. Insulin mediated peripheral glucose disposal is markedly impaired [13] at a post-insulin receptor level. Both oxidative and non-oxidative pathways of glucose disposal are reduced by glucocorticoids [14], with an accompanying reduction of muscle glycogen synthase activity [15]. Furthermore glucocorticoids also induce hepatic insulin resistance [13]. Thus, the insulin resistance induced by glucocorticoids has some resemblance to that seen in established NIDDM patients [37]. In the current study, in response to dex in both the relative and control groups, the insulin sensitivities were severely reduced but to a similar level even though the Si was significantly higher in the control subjects before treatment. This was reflected by the significant correlation between the fall in $\mathrm{Si}$ and the pre-dex $\mathrm{Si}$ in all subjects, as noted also by others [33]. Thus, post-dex, the beta cell was "stressed" by the same degree of insulin resistance, i.e. between 0.2 and $0.410^{-4} \cdot \mathrm{min}^{-1}$ per pmol/l (Fig. 4), in all subjects, and yet glucose tolerance deteriorated more notably in only a subset of seven relatives (Fig. 2). These seven subjects did not differ from either the "normoglycaemic" relatives or the control subjects with regard to Si before or after dex. Rather, first phase insulin secretion $(\varnothing 1)$ and acute insulin response to i.v. glucose $\left(A I R_{\text {glucose }}\right)$ and oral glucose $\left(\Delta \mathrm{I}_{30}\right)$ were significantly reduced in absolute terms in these hyperglycaemic relatives compared to the normoglycaemic relatives and the control subjects after exposure to dex. However, even more importantly, their acute phase insulin release was also reduced before treatment with dex. This is well illustrated in Figure 4 where the hyperbolic relationship [27, 32] between $\mathrm{Si}$ and insulin secretion is shown. In response to dex the normoglycaemic relatives and the control subjects almost completely compensated for the dex-induced insulin resistance by an appropriate increase of insulin secretion as shown by the open triangle and circles respectively. In contrast, the hyperglycaemic relatives could not increase insulin secretion to a sufficient extent post-dex and are located well away from the normal range insulin secretion/Si curve (open square), which contributes to their decreased oral glucose tolerance during dex. Thus, when the glucose assimilation index is calculated, which is a measure of whole body insulin mediated glucose disposal $[27,32]$, the hyperglycaemic relatives were found to have a decreased value, again both before and during dex treatment. However, the decrease in insulin mediated glucose disposal in the hyperglycaemic relatives as reflected by the reduced glucose assimilation index is solely explained by the decreased preand post-dex first phase insulin responsiveness $(\varnothing 1)$.

Several studies have reported insulin resistance and hyperinsulinaemia in normoglycaemic relatives of NIDDM patients $[4,6,38,39]$, whereas only a few studies have reported the presence of hypoinsulinaemia $[7,10,40,41]$, including our recent study of identical twins discordant for NIDDM [9]. However, most studies have not taken into account the prevailing insulin resistance when examining the insulin response [7, 42]. Prospective studies regarding the development of NIDDM in genetically prone individuals are also conflicting [5,8]. In a longitudinal study by Martin et al. [5] a low initial Si and a low glucose effectiveness were predictors of future NIDDM, whereas hypoinsulinaemia was not, but insulin secretion was not corrected for the insulin resistance of the subjects. More recently, it was demonstrated that a low insulin response, corrected for insulin resistance and obesity, was a separate predictor of future NIDDM in Pima Indians [8], who are known generally to be hypersecretors of insulin (corrected for their insulin resistance) as a population group [8]. Furthermore, in a study by Haffner et al. [43] a low OGTT $\Delta \mathrm{I}_{30} / \mathrm{G}_{30}$ corrected for fasting insulin concentration was found to be a predictor of future impaired glucose treatment. These latter studies therefore support our finding that failure of the beta cell to respond to the dex-induced insulin resistance is a key factor in the development of glucose intolerance and is possibly "genetically" pre-determined. This conclusion is also supported by our observation that before exposure to dex there was a decreased insulin mediated glucose disposal in the relatives, as defined by $\mathrm{Si} \times \varnothing 1$, which was compensated for by the enhanced glucose mediated glucose disposal [7]. In addition, with the stress of dex-induced severe insulin resistance, absolute first phase insulin secretion was not increased to a sufficient degree in the hyperglycaemic relatives and, because the glucose-mediated glucose disposal $(\mathrm{Sg})$ compensatory mechanism failed to increase further it was unable to overcome the worsening insulin mediated glucose disposal $(\mathrm{Si} \times \varnothing 1)$, glucose tolerance decreased in these relatives. However, from the present data it is not possible to conclude whether the inability of the beta cell to respond to dex-induced acute stress is an inherited defect or not. In a recent study of Wajngot et al. [44] dex was shown to be more diabetogenic in low insulin responders, as determined by a fixed glucose infusion, than in high insulin responders [44]. Although these subjects were not characterised with regard to family history for diabetes, the authors concluded that the magnitude of the insulin response during dex treatment might allow a differentiation by low insulin response of those subjects who may have an increased risk of NIDDM [44]. Recently [17] it was shown in 
normal subjects without any family history of NIDDM that dex treatment at two different doses (6 or $18 \mathrm{mg}$ in total for 3 days) produced nearly equal reductions in $\mathrm{Si}$. At the low dose no significant change occurred in the $\mathrm{Kg}$ value whereas at the high dose (which was nearly identical to the total 20-mg dose used in the present study) a significant fall was observed in the $\mathrm{Kg}$ value. The latter was solely explained by a reduction in the insulin response to the prevailing insulin resistance, but none of these normal subjects without a family history of NIDDM developed severe glucose intolerance during the high dex dose [17]. In the present study, our hyper-rel subgroup of the relatives had a greater reduction in insulin secretion as compared to the former study [17] and therefore these relatives developed severe glucose intolerance or frank diabetes. Furthermore, in a study by Ekstrand et al. [45] in steroid-treated kidney transplant patients a decreased insulin secretion was noted only in those patients who developed diabetes after the transplantation, and a higher proportion of these "diabetic" patients had a positive family history for NIDDM as compared to the transplant patient who did not develop diabetes after transplantation [45]. Nevertheless, from the current cross-sectional study, it is not possible to conclude that our dex-induced hyperglycaemic relatives of NIDDM are at risk of developing future overt NIDDM. Prospective studies of such individuals are required but the earlier studies of Fajan et al. [18], Conn and Fajans [19] and Rull et al. [20] might support that these hyperglycaemic relatives are at increased risk.

At the clinical level, the relatives who developed severe glucose intolerance during dex treatment were noted to have significantly elevated pre-dex fasting triglyceride concentration and LDL/HDL ratio. Interestingly, when the significant positive correlation between the pre-dex fasting triglyceride level and the post-dex 2-h OGTT plasma glucose concentration in the relatives was combined with the re-

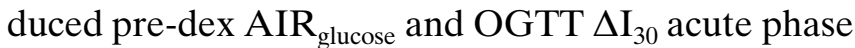
insulin release in a multiple regression model of independent predictors of dex-induced raised 2-h OGTT glucose levels, a strong relationship was noted in the relatives, with a prediction capability of around 60 $70 \%$.

In conclusion, glucose tolerance of normoglycaemic relatives of NIDDM patients responds differently to dex treatment, as compared to subjects without any family history of diabetes. On exposure to dex about $35 \%$ of relatives developed transient glucose intolerance which was due primarily to a reduced absolute insulin secretory response to the insulin resistance, despite a similarly reduced $\mathrm{Si}$ in relatives and control subjects following exposure to dex. Importantly the reduced insulin secretory capacity was present in susceptible relatives both before and after dex treatment. Although former studies [19] have indicated that a normal insulin response to steroids is associated with a markedly reduced risk of future NIDDM, it remains to be determined whether an acute dex test is able to predict prospectively those relatives of NIDDM patients who are at risk or not of developing future diabetes. It does, however, appear that the beta cell is a key player in the development of future diabetes.

Acknowledgements. The authors would like to acknowledge the expert technical assistance of Charlotte Fage Larsen, Henny Hansen, Henriette Vorup and Karin Dyregaard. The study was supported by grants from the Danish Diabetes Association, Diabetes Australia Research Foundation, the National Health and Medical Research Council of Australia, the NovoNordisk Foundation, Direktør Jacob Madsen and hustru Olga Madsens Fond, Fonden til Lægevidenskabens Fremme, the Danish Research Council and from the Clinical Research Institute, Odense University Hospital.

\section{References}

1. Beck Nielsen H, Groop LC (1994) Metabolic and genetic characterization of prediabetic states. Sequence of events leading to non- insulin-dependent diabetes mellitus. J Clin Invest 94: 1714-1721

2. Porte DJ (1991) Banting lecture 1990. Beta-cells in type II diabetes mellitus. Diabetes 40: 166-180

3. Kobberling J, Tillil H (1982) Empirical risk figures for firstdegree relatives of non-insulin dependent diabetics. In: Kobberling J, Tattersall R (eds) The genetics of diabetes mellitus. Academic Press, London New York, pp 202-209

4. Eriksson J, Franssila Kallunki A, Ekstrand A et al. (1989) Early metabolic defects in persons at increased risk for non-insulin-dependent diabetes mellitus. N Engl J Med 321: 337-343

5. Martin BC, Warram JH, Krolewski AS, Bergman RN, Soeldner JS, Kahn CR (1992) Role of glucose and insulin resistance in development of type 2 diabetes mellitus: results of a 25-year follow-up study. Lancet 340: 925-929

6. Vaag A, Henriksen JE, Beck Nielsen H (1992) Decreased insulin activation of glycogen synthase in skeletal muscles in young nonobese Caucasian first-degree relatives of patients with non-insulin-dependent diabetes mellitus. J Clin Invest 89: 782-788

7. Henriksen JE, Alford F, Handberg A et al. (1994) Increased glucose effectiveness in normoglycemic but insulin-resistant relatives of patients with non-insulin-dependent diabetes mellitus. A novel compensatory mechanism. J Clin Invest 94: 1196-1204

8. Lillioja S, Mott DM, Spraul M et al. (1993) Insulin resistance and insulin secretory dysfunction as precursors of non-insulin- dependent diabetes mellitus. Prospective studies of Pima Indians. N Engl J Med 329: 1988-1992

9. Vaag A, Henriksen JE, Madsbad S, Holm N, Beck-Nielsen $\mathrm{H}$ (1995) Insulin secretion, insulin action, and hepatic glucose production in identical twins discordant for noninsulin-dependent diabetes mellitus. J Clin Invest 95: 690698

10. Pimenta W, Korytkowski M, Mitrakou A et al. (1995) Pancreatic beta-cell dysfunction as the primary genetic lesion in NIDDM: evidence from studies in normal glucose-tolerant individuals with a first degree NIDDM relative. J Am Med Assoc 273: 1855-1861 
11. DeFronzo RA (1988) Lilly lecture 1987. The triumvirate: beta-cell, muscle, liver. A collusion responsible for NIDDM. Diabetes 37: 667-687

12. Yki Jarvinen H (1994) Pathogenesis of non-insulin-dependent diabetes mellitus. Lancet 343: 91-95

13. McMahon M, Gerich J, Rizza R (1988) Effects of glucocorticoids on carbohydrate metabolism. Diabetes Metab Rev 4: $17-30$

14. Tappy L, Randin D, Vollenweider P et al. (1994) Mechanisms of dex-induced insulin resistance in healthy humans. J Clin Endocrinol Metab 79: 1063-1069

15. Coderre L, Srivastava AK, Chiasson JL (1992) Effect of hypercorticism on regulation of skeletal muscle glycogen metabolism by epinephrine. Am J Physiol 262: E434-E439

16. Khan A, Ostenson CG, Berggren PO, Efendic S (1992) Glucocorticoid increases glucose cycling and inhibits insulin release in pancreatic islets of ob/ob mice. Am J Physiol 263: E663-E666

17. Matsumoto K, Yamasaki H, Akazawa S et al. (1996) Highdose but not low-dose dex impairs glucose tolerance by inducing compensatory failure of pancreatic beta-cells in normal men. J Clin Endocrinol Metab 81: 2621-2626

18. Fajans SS, Conn JW, Arbor A (1954) An approach to the prediction of diabetes mellitus by modification of the glucose tolerance test with cortisone. Diabetes 3: 296-304

19. Conn JW, Fajans SS (1961) The prediabetic state. A concept of dynamic resistance to a genetic diabetogenic influence. Am J Med 31: 839-850

20. Rull JA, Conn JW, Floyd JCJ, Fajans SS (1970) Levels of plasma insulin during cortisone glucose tolerance tests in "nondiabetic" relatives of diabetic patients. Implications of diminished insulin secretory reserve in subclinical diabetes. Diabetes 19: 1-10

21. Bergman RN, Ider YZ, Bowden CR, Cobelli C (1979) Quantitative estimation of Si. Am J Physiol 236: E667-E677

22. Toffolo G, Bergman RN, Finegood DT, Bowden CR, Cobelli C (1980) Quantitative estimation of beta cell sensitivity to glucose in the intact organism: a minimal model of insulin kinetics in the dog. Diabetes 29: 979-990

23. Lukaski HC, Johnson PE, Bolonchuk WW, Lykken GI (1985) Assessment of fat-free mass using bioelectrical impedance measurements of the human body. Am J Clin Nutr 41: 810-817

24. Hemmilä I, Dakubu S, Mukkala V, Siitari H, Lövgren T (1984) Europium as a label in time-resolved immunofluorometric assays. Anal Biochem 137: 335-343

25. Martin IK, Weber KM, Ward GM, Best JD, Boston RC (1990) Application of the SAAM modeling program to minimal model analysis of intravenous glucose tolerance test data. Comput Methods Programs Biomed 33: 193-203

26. Boston RC, Greif PC, Berman M (1981) Conversational SAAM-an interactive program for kinetic analysis of biological systems. Comput Programs Biomed 13: 111-119

27. Kahn SE, Prigeon RL, McCulloch DK et al. (1993) Quantification of the relationship between $\mathrm{Si}$ and beta-cell function in human subjects. Evidence for a hyperbolic function. Diabetes 42: 1663-1672

28. Weber KM, Martin IK, Best JD, Alford FP, Boston RC (1989) Alternative method for minimal model analysis of intravenous glucose tolerance data. Am J Physiol 256: E524-E535
29. Boston RC, Weber KM (1984) Modeling with SAAM and its advancement in association with mineral metabolism. Math Biosc 72: 191-198

30. Berman M (1963) The formulation and testing of models. Ann N Y Acad Sci 108: 182-194

31. Kahn SE, Prigeon RL, McCulloch DK et al. (1994) The contribution of insulin-dependent and insulin-independent glucose uptake to intravenous glucose tolerance in healthy human subjects. Diabetes 43: 587-592

32. Bergman RN (1989) Lilly lecture 1989. Toward physiological understanding of glucose tolerance. Minimal-model approach. Diabetes 38: 1512-1527

33. Baron AD, Wallace P, Brechtel G (1987) In vivo regulation of non-insulin-mediated and insulin mediated glucose uptake by cortisol. Diabetes 36: 1230-1237

34. Kautzky Willer A, Thomaseth K, Clodi M et al. (1996) Beta-cell activity and hepatic insulin extraction following dexamethasone administration in healthy subjects. Metabolism 45: 486-491

35. Vaag A, Alford F, Henriksen FL, Christopher M, BeckNielsen H (1995) Multiple defects of both hepatic and peripheral intracellular glucose processing contributes to the hyperglycemia of NIDDM. Diabetologia 38: 326-336

36. Christopher MJ, Rantzau C, Ward GM, Alford FP (1995) Insulinopenia and hyperglycemia influence the in vivo partitioning of GE and SI. Am J Physiol 268: E410-E421

37. Beck Nielsen H, Vaag A, Damsbo P et al. (1992) Insulin resistance in skeletal muscles in patients with NIDDM. Diabetes Care 15: 418-429

38. Osei K, Cottrell DA, Orabella MM (1991) Insulin sensitivity, glucose effectiveness, and body fat distribution pattern in nondiabetic offspring of patients with NIDDM. Diabetes Care 14: 890-896

39. Gulli G, Ferrannini E, Stern M, Haffner S, DeFronzo RA (1992) The metabolic profile of NIDDM is fully established in glucose-tolerant offspring of two Mexican-American NIDDM parents. Diabetes 41: 1575-1586

40. O'Rahilly SP, Nugent Z, Rudenski AS et al. (1986) Betacell dysfunction, rather than insulin insensitivity, is the primary defect in familial type 2 diabetes. Lancet 2: 360364

41. O'Rahilly S, Turner RC, Matthews DR (1988) Impaired pulsatile secretion of insulin in relatives of patients with non-insulin-dependent diabetes. N Engl J Med 318: 12251230

42. Johnston C, Ward WK, Beard JC, McKnight B, Porte DJ (1990) Islet function and insulin sensitivity in the non-diabetic offspring of conjugal type 2 diabetic patients. Diabet Med 7: 119-125

43. Haffner SM, Miettinen H, Gaskill SP, Stern MP (1996) Decreased insulin action and insulin secretion predict the development of impaired glucose tolerance. Diabetologia 39: 1201-1208

44. Wajngot A, Giacca A, Grill V, Vranic M, Efendic S (1992) The diabetogenic effects of glucocorticoids are more pronounced in low- than in high-insulin responders. Proc Natl Acad Sci U S A 89: 6035-6039

45. Ekstrand AV, Eriksson JG, Gronhagen Riska C, Ahonen PJ, Groop LC (1992) Insulin resistance and insulin deficiency in the pathogenesis of posttransplantation diabetes in man. Transplantation 53: 563-569 